criteria can be used to deny early closure to babies who will probably die within the first few weeks or who would have a quality of life so poor as not to merit survival. This second group is larger than the first and its selection may well involve the doctor in a commitment to actively or passively limit the infants' survival.

Our experience in 1972 shows that it is possible to predict a few of the babies who will succumb quickly, and, taken with still births, this fraction of about a fifth of all infants born with myeloceles presents few ethical problems. Our policy did mean, however, that many severely affected babies survived early closure to live with extreme handicaps. Analysis of the 1973 figures shows that when a larger group is excluded from early closure of myelocele it is not possible to predict accurately which babies will die in the first few months. Of our patients denied early closure of the myelocele $30^{\circ}$ " survived at least one year, and all except one had valves inserted. Some of these babies seem to be intellectually normal, but we do not yet have enough information about them to make predictions of their quality of life, though, certainly, their physical handicap will be severe.

In the light of these figures the explicit point needs to be made that early closure of a myelocele is not a life-saving procedure and that denial of early closure is not synonymous with early death. Rather than myelocele closure being the key to potential survival it is the drainage of hydrocephalus that is the critical procedure determining survival. Our figures, which show that no baby denied both early closure and insertion of a valve survived more than 13 months, and those of Lorber, ${ }^{*}$ which show that no baby denied both procedures survived longer than nine months, support this concept. Indeed, deaths after the first few months in babies with unoperated myeloceles are usually directly or indirectly a consequence of hydrocephalus.

Hence the medical and ethical debates on the early management of infants with spina bifida should centre on the indications for treating hydrocephalus rather than the pros and cons of early myelocele closure. A possible advantage of such a shift of emphasis is that no longer would decisions made at birth apply for the rest of an infant's life. Instead, decisions on management could be reviewed at regular intervals as determined by the patient's individual condition, as is general to medical practice.

In this unit every baby referred is assessed by the surgical team and a member of the paediatric neurological team. We have evolved the practice of recommending for early closure of the myelocele those infants with useful preservable leg movements who are in good general condition. Other babies may be subjected to early closure if there is overriding parental pressure for this despite medical advice. The pathways of both groups of infants (operated and unoperated) then run in parallel. Both groups are followed up and have whatever medical or surgical management (including insertion of a valve) their condition indicates. Thus babies denied early closure who survive the first few weeks and are in good general condition are considered for insertion of a valve and other procedures to improve their quality of life if their general condition warrants this. By the same token, babies who initially underwent early closure who later develop complications leading to severe irreversible handicap may be denied further desperate procedures.

Children with other forms of physically and mentally handicapping conditions are progressively assessed and managed by most doctors in this country in this way and there is no reason for managing babies with myeloceles in a totally different manner.

\section{References}

${ }^{1}$ Lorber, J, Archives of Disease in Childhood, 1972, 47, 854.

2 Laurence, K M, Developmental Medicine and Child Neurology, 1966, suppl $11, \mathrm{p} 10$

${ }^{3}$ Laurence, K M, and Tew, B J, Archives of Disease in Childhood, 1971, 46, 127.

${ }^{4}$ Knox, E G, Development Medicine and Child Neurology, 1967, suppl 13, p 14.

Smith, G K, and Smith, E D, British Medical fournal, 1973, 4, 189.

" Stark, G D, and Drummond, M, Archives of Disease in Childhood, 1973, $48,676$.

Sharrard, W J W, et al, Archives of Disease in Childhood, 1963, 38, 18.

" Lorber, J, British Medical fournal, 1973, 4, 201.

"Stein, C S, Schut. L, and Ames, M D, Pediatrics, 1974, 54, 553.

\title{
Transport of newborn infants for intensive care
}

\author{
A M BLAKE， N McINTOSH， E O R REYNOLDS， D ST ANDREW
}

British Medical fournal, 1975, 4, 13-17

\begin{abstract}
Summary
During the three years 1972-4 222 newborn infants were transported to this hospital for intensive care. They were collected by trained staff using a specially modified transport incubator with an in-built mechanical ventilator and facilities for monitoring body temperature, heart rate, and inspired oxygen concentration. Two of the infants came from home and the rest from 41 hospitals from half a mile $(0.8 \mathrm{~km})$ to 50 miles $(80.5 \mathrm{~km})$ (median
\end{abstract}

\footnotetext{
Department of Paediatrics, University College Hospital and Medical School, London WC1

A M BLAKE, RSCN, nursing officer

N MCINTOSH, MRCP, senior registrar

E O R REYNOLDS, FRCP, consultant paediatrician

Department of Medical Physics, University College Hospital Medical School, London WC1

D ST ANDREW, MIERE, electronics engineer
}

eight miles $(12.9 \mathrm{~km})$ ) away. The mean birth weight of the infants was $1702 \mathrm{~g}$ (range 520-4040 g) and their mean gestational age was 32 weeks (range 24-42 weeks). The principal reasons for referral were low birth weight and severe respiratory illnesses. Altogether $109(49 \%)$ of the infants needed mechanical ventilation in transit and another $38(17 \%)$ needed it later. During the journey the condition of $88(40 \%)$ of the infants was thought to improve, in $125(56 \%)$ it was static and in nine $\left(4^{\%} \%\right)$ four of whom died-it deteriorated. A total of 142 infants $\left(64^{\circ}{ }_{0}\right)$ survived the neonatal period. There was no correlation between the distance travelled and the survival rate.

Seriously ill newborn infants may be transported safely to a referral centre within a radius of $\mathbf{5 0}$ miles, and the risks of the journey are negligible compared with the risks of leaving the infant in a hospital that is not staffed or equipped for neonatal intensive care.

\section{Introduction}

The successful management of infants of low birth weight or those who are seriously ill requires techniques similar to those 
used in adult intensive care units. ${ }^{1}$ For example, the infant's thermal environment must be precisely controlled, and his breathing, heart rate, and blood pressure often have to be monitored. Fluid and calorie requirements are met by tubefeeding, intravascular infusions, and, in the smallest and most severely ill infants, total parenteral nutrition. Inspired oxygen concentration and arterial oxygen tension must be estimated repeatedly, so that the dangers of hypoxia (death or permanent damage to the brain) and hyperoxia (retrolental fibroplasia) may be avoided. Infection, abnormalities of haemostasis, and acidbase or electrolyte imbalance need urgent diagnosis and treatment, and jaundice may necessitate phototherapy or exchange transfusion. Infants with hyaline membrane disease or apnoeic attacks often need treatment with continuous positive airway pressure $(\mathrm{CPAP})^{2}$ or mechanical ventilation.

Infants requiring this sort of care can be properly looked after only in a unit with ample medical and nursing staff, equipment, and laboratory and radiological support. ${ }^{13-7}$ Since admissions and emergencies may occur at any time a 24-hour service has to be provided. The number of infants born in the average maternity hospital who require such a service is small ${ }^{3}$ ? and to set up an intensive care unit in every maternity hospital would clearly be uneconomical. For this reason the Expert Group on Special Care for Babies ${ }^{3}$ in 1971 recommended that there should be a "two-tier" system of neonatal care in England and Wales, with "special care nurseries" in all district general hospitals, which could deal with most neonatal problems, and a smaller number of "intensive care nurseries," with much greater resources, sited in hospitals with major obstetric units. It was envisaged that, when possible, women with high-risk pregnancies should be delivered in these centres; failing this, the intensive care nurseries should be responsible for transporting and looking after the smallest and most severely ill infants.

The neonatal unit of this hospital has been admitting sick newborn infants from other maternity hospitals for over 10 years. Since 1974 it has acted as a regional intensive care nursery for the North-east Thames Region. To assess the effectiveness of our transport system, and the outcome for the infants, we analysed data from all infants referred from other hospitals in the three years 1972-4. The results are reported here.

\section{Methods}

When a telephoned request for the transfer of a sick infant is received details are obtained of the diagnosis and general state of the infant. If appropriate, advice is given about how to keep him in optimum condition until he is collected. An ambulance is called and members of the staff of the neonatal unit, usually a doctor and a nurse, but sometimes two nurses, travel in the ambulance to the referring hospital, taking with them a transport incubator and all the equipment necessary for safe transfer. ${ }^{4-7}$ If the journey is long or much traffic is expected a police escort is requested so that the ambulance can get to the referring hospital as rapidly as possible. When the birth of a highrisk infant can be forseen we ask to be told in advance so that our staff can be present at the delivery.

\section{TRANSPORT INCUBATOR}

The transport incubator used in the early months of the study was the Series III Oxygenaire portable incubator with an attached Vickers infant mechanical ventilator. ${ }^{8}$ Subsequently a modified Vickers Model 77 portable incubator has been used. It has facilities for warming the infant which can be run from a $220-240$ volt or a 12 -volt source. A $24-\mathrm{ft}^{3}\left(0.68 \mathrm{~m}^{3}\right)$ oxygen cylinder is incorporated so that any desired inspired oxygen concentration can be given to a spontaneously breathing infant, and there is an in-built battery-powered mechanical ventilator. This ventilator is a constant-pressure generator and is equipped with a pressure gauge. It is designed so that peak airway pressure, inspiration time, and expiration time can be independently regulated, and a positive end-expiratory pressure can be obtained by fitting a gate clamp over the expiratory tubing. The ventilator can also provide a flow of gas suitable for administering CPAP if the cycling mechanism is turned off. The ventilator is supplied with compressed air or oxygen from gas cylinders but there is no air-oxygen blender. When oxygen is used a venturi allows regulation of the inspired oxygen concentration between about $65 \%$ and $100 \%$. Lower inspired oxygen concentrations can be obtained by using two flow meters to regulate the supply of air and oxygen from separate cylinders, but this is cumbersome.

Monitoring devices have been built into the transport incubator by the medical physics department of this hospital. To make space available the humidifier (which is designed to humidify the gas inside the incubator but not that supplying the ventilator) has been removed, since we do not regard it as vital that the infant should travel in a highly humidified atmosphere, and meter displays of inspired oxygen concentration, body temperature, and heart rate have been fitted into the humidifier compartment. Each heart beat is also indicated by a flashing light. Removable circuit boards supplying the displays are built into one of the equipment drawers. We have mounted the incubator on a perambulator chassis so that it can be wheeled easily over rough ground, but it remains detachable for carrying up stairs should the need arise. All the necessary equipment for resuscitation, intravascular infusions, measurement of blood glucose, and dealing with emergencies ${ }^{4-7}$ is carried in a plastic tool box on a wire tray mounted on the chassis.

\section{PROCEDURE AT REFERRING HOSPITAL}

The infant's condition is assessed and appropriate treatment given. Particular attention is paid to ensuring adequate oxygenation and warmth, and if the infant is in a collapsed state and known or suspected to have a very severe metabolic acidosis after hypoxia small $(2-5 \mathrm{ml})$ doses of $5 \%(600 \mathrm{mmol} / \mathrm{l})$ sodium bicarbonate solution are sometimes given intravascularly. The blood glucose level is measured with Dextrostix and hypoglycaemia corrected by oral or intravenous glucose solutions. If the infant's breathing seems precarious he is intubated with a Warne No. 12 oroendotracheal tube fitted through a cut-off tracheostomy tube and attached to a gauze hat. We prefer this system to using a nasotracheal tube because it is quicker to set up. The endotracheal tube is then connected to the mechanical ventilator. Infants with hyaline membrane disease (the most common illness requiring mechanical ventilation) are usually ventilated with $100 \%$ oxygen and with the following ventilator settings: peak airway pressure $2 \cdot 0-2.5 \mathrm{kPa}\left(20-25 \mathrm{~cm} \mathrm{H}_{2} \mathrm{O}\right)$; inspiration :expiration ratio $1: 1$ or $2: 1$; and respiratory frequency $30 /$ minute. ${ }^{9}$ Positive end-expiratory pressures have only occasionally been used, partly because of the inadequate method available for applying them and partly because the settings described above have proved satisfactory. We have not used CPAP during transfer, believing that it is wiser to ensure adequate ventilation as well as oxygenation during the journey. Infants with normal lungs or respiratory illnesses other than hyaline membrane disease requiring ventilation are usually ventilated with lower peak airway pressures, inspiration:expiration ratios, and inspired oxygen concentrations. Electrodes are taped to the infants' limbs or chest so that the heart rate can be monitored and a rectal or skin temperature probe is placed in position. The infant is then wrapped in Gamgee tissue and a "silver swaddler." 10 Any intravascular infusions in progress are maintained for the journey. Referring hospitals are given a supply of questionnaire forms on which to enter details of the mother's and infant's histories. These forms are completed and, when permitted, $\boldsymbol{x}$-ray pictures and case notes are borrowed. Before leaving the referring hospital every effort is made to show the infant, in the portable incubator, to the parents, and to explain the likely course of his illness. The parents are also given a map showing them how to reach our neonatal unit and the unit's telephone number.

\section{RETURN JOURNEY}

Because the infant's condition is stabilised at the referring hospital there is usually no reason for the ambulance to travel fast on the return journey. An important advantage of travelling relatively slowly (30-40 mph (48-64 $\mathrm{kph})$ ) is that the infant and the incubator are not seriously shaken about. While in transit the oxygen supply of the transport incubator can be spared by using the ambulance's oxygen cylinder. After arrival back at this hospital the infant is transferred to a previously prepared incubator or placed under a radiant heat source. Superficial swabs are sent for bacterial culture and subsequent management is no different from that of infants born in this hospital. Referred infants are usually nursed in cubicles until it is clear that they are not carrying dangerous pathogenic organisms.

The parents and siblings are encouraged to visit the infant as often 
as possible and to participate in his care. When the mother is still in the referring hospital we usually give the father a photograph of the infant to take to her. The infant is often transferred back to the referring hospital when he is out of immediate danger.

\section{Results}

During 1972-4 222 newborn infants were transported to this hospital. Two were collected from home, where they had been born, and the rest came from 41 hospitals from half a mile $(0.8 \mathrm{~km})$ to 50 miles $(80.5 \mathrm{~km})$ (median eight miles $(12.9 \mathrm{~km})$ ) away. Altogether 106 infants were born in 18 hospitals in the North-east Thames Region and 114 came from 23 hospitals in other regions. Between one and 21 (median three) infants were referred from each hospital.

BIRTH WEIGHT, GESTATIONAL AGE, AND SURVIVAL RATE

One hundred and twenty of the infants were boys and 102 were girls. Their mean birth weight was $1702 \mathrm{~g}$ (range 530-4040 g) and their mean gestational age 32 weeks (range 24-42 weeks). Fifteen (7\%) weighed less than the 10th centile for gestation. ${ }^{11}$ Of the 142 infants $(64 \%)$ who survived the neonatal period (28 days) $10(5 \%)$ died later, leaving 132 infants $(60 \%)$ who were alive from six months to three and a half years after birth.

Table I gives neonatal survival rates by birth weight. Figures for infants born in this hospital who required admission to the neonatal unit because of low birth weight or illness and for all infants born in England and Wales are shown for comparison. Survival by gestational age is given in table II. The principal diagnoses of the referred infants are shown in table III. The ages at which the requests for transfer were received are given in table VI, together with the distance travelled and the numbers of infants who survived.

TABLE I-Birth weight and neonatal survival (more than 28 days) of transported infants, of infants born in this hospital who required admission to neonatal unit, and of whole population born in England and Wales

\begin{tabular}{|c|c|c|c|c|c|}
\hline \multirow{3}{*}{$\begin{array}{c}\text { Birth } \\
\text { weight } \\
\text { (g) }\end{array}$} & \multicolumn{4}{|c|}{ Infants admitted to neonatal unit, 1972-4 } & \multirow{3}{*}{$\begin{array}{l}\text { Survival o } \\
\text { all infants } \\
\text { born in } \\
\text { England } \\
\text { and Wales } \\
1972-3 \ddagger\end{array}$} \\
\hline & \multicolumn{2}{|c|}{ Transported* } & \multicolumn{2}{|c|}{ Born in $\mathrm{UCH} \dagger$} & \\
\hline & Total & Survived & Total & Survived & \\
\hline $\begin{array}{l}501-1000 \\
1001-1500 \\
1501-2000 \\
2001-2500 \\
>2500\end{array}$ & $\begin{array}{l}33 \\
73 \\
48 \\
36 \\
32\end{array}$ & $\begin{array}{l}12(36 \%) \\
40(55 \%) \\
39(81 \%) \\
25(69 \%) \\
26(81 \%)\end{array}$ & $\begin{array}{r}21 \\
53 \\
103 \\
267 \\
659\end{array}$ & $\begin{array}{r}6(29 \%) \\
41(77 \%) \\
98(95 \%) \\
257(96 \%) \\
645(98 \%)\end{array}$ & $\begin{array}{l}21 \% \\
58 \% \\
87 \% \\
97 \% \\
99 \%\end{array}$ \\
\hline Total & 222 & $142(64 \%)$ & 1103 & $1047(95 \%)$ & $99 \%$ \\
\hline
\end{tabular}

*Four transported infants who died during journey are included as "admitted" in

this and tables II to V.
tAll infants weighing $2000 \mathrm{~g}$ or less were admitted; larger infants were admitted only if they were ill or if a period of observation was thought advisable.

Figures for 1974 were not available.

\section{CONDITION OF THE INFANTS WHEN COLLECTED}

From November 1973 a special form was filled in at the time of transfer describing the general condition of the infants when they were collected and giving details of the journey. Information about infants transferred before this was obtained from the case notes. Eighty-six infants were in "good" condition, as judged by the absence of cyanosis, a normal heart rate, and adequate spontaneous breathing or satisfactory intermittent positive-pressure ventilation via an endotracheal tube or face mask. Seventy-three $(85 \%)$ of these infants
TABLE II-Gestational age and neonatal survival of transported infants

\begin{tabular}{c|c|c||c|c|c}
\hline $\begin{array}{c}\text { Gestational } \\
\text { age } \\
\text { (weeks) }\end{array}$ & $\begin{array}{c}\text { Total } \\
\text { No. of } \\
\text { infants }\end{array}$ & $\begin{array}{c}\text { Proportion } \\
\text { survived }\end{array}$ & $\begin{array}{c}\text { Gestational } \\
\text { age } \\
\text { (weeks) }\end{array}$ & $\begin{array}{c}\text { Total } \\
\text { No. of } \\
\text { infants }\end{array}$ & $\begin{array}{c}\text { Proportion } \\
\text { survived }\end{array}$ \\
\cline { 1 - 2 } $24-5$ & 5 & $1(20 \%)$ & $32-3$ & 35 & $27(77 \%)$ \\
$26-7$ & 23 & $7(30 \%)$ & $34-5$ & 28 & $21(75 \%)$ \\
$28-9$ & 33 & $14(42 \%)$ & $36-7$ & 23 & $19(83 \%)$ \\
$30-1$ & 45 & $31(69 \%)$ & $38-42$ & 30 & $22(73 \%)$ \\
\hline
\end{tabular}

TABLE III-Principal diagnoses of referred infants. Many infants appear under more than one heading

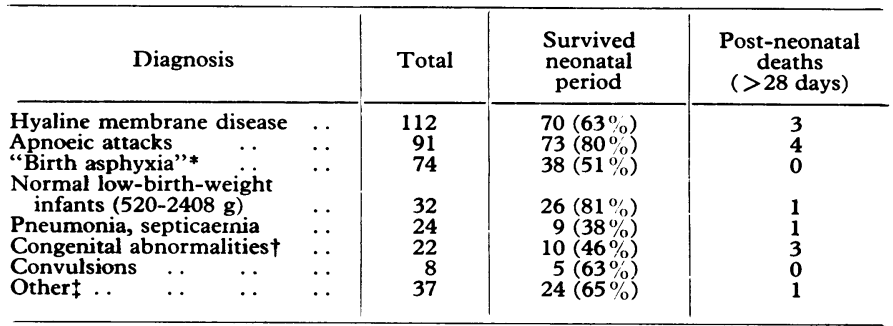

*Apgar score 4 or less at 1 minute of age and 6 or less at 5 minutes, or condition at delivery describr less at 1 minute of age and 6 or less at 5 minutes, or condition at for more than 15 minutes.

tThe abnormalities were considered lethal in 13 infants, usually because they were multiple or included inoperable heart malformations.

IIncluded poor intrauterine growth, transient tachypnoea, surgical problems, hypothermia, rhesus haemolytic disease, jaundice, anaemia, pulmonary haemorrhage,

survived the neonatal period. Sixty-six infants, $40(61 \%)$ of whom survived, were in "moderate" condition, with-for example, mild cyanosis and irregular breathing - and 70 infants, only $29(42 \%)$ of whom survived, were in "bad" condition, with severe cyanosis or peripheral vasoconstriction and often apnoea and bradycardia. Among those in a bad condition cardiac arrest had occurred in six who were then successfully resuscitated. Seventy-eight $(35 \%)$ of the infants were already being given intermittent positive-pressure ventilation in the referring hospitals, usually from a resuscitation trolley via an endotracheal tube. The method of ventilation or oxygenation being used seemed inadequate in 44 of these 78 infants because their condition immediately improved when they were connected to the portable ventilator. A further 15 infants with severe respiratory failure were not being ventilated because facilities or staff were not available in the referring hospitals. These 15 infants, and another 16 with serious pulmonary illnesses or apnoeic attacks whose condition suggested that they might deteriorate badly during the journey, were electively intubated and ventilated, giving a total of 109 infants $(49 \%$ of the whole population) who were ventilated in transit. Survival rates for these infants and for other infants who required mechanical ventilation later are given in table $\mathrm{V}$.

TABLE V-Survival rates of infants given mechanical ventilation (MV)

\begin{tabular}{c|c|c|c|c|c|c}
\hline \multirow{2}{*}{$\begin{array}{c}\text { Birth } \\
\text { weight } \\
(\mathrm{g})\end{array}$} & \multicolumn{2}{|c|}{$\begin{array}{c}\text { MV during and } \\
\text { after transfer }\end{array}$} & \multicolumn{2}{c|}{$\begin{array}{c}\text { MV started } \\
\text { after transfer }\end{array}$} & \multicolumn{2}{c}{$\begin{array}{c}\text { All infants } \\
\text { requiring MV }\end{array}$} \\
\cline { 2 - 7 } & Total & Survived & Total & Survived & Total & Survived \\
\hline $501-1000$ & 14 & 1 & 13 & 5 & 27 & $6(22 \%)$ \\
$1001-1500$ & 39 & 15 & 10 & 3 & 49 & $18(37 \%)$ \\
$1501-2000$ & 30 & 22 & 3 & 2 & 33 & $24(73 \%)$ \\
$2001-2500$ & 19 & 11 & 4 & 3 & 23 & $14(61 \%)$ \\
$>2500$ & 7 & 4 & 8 & 6 & 15 & $10(67 \%)$ \\
\hline Total & 109 & $53(49 \%)$ & 38 & $19(50 \%)$ & 147 & $72(49 \%)$ \\
\hline
\end{tabular}

TABLE IV-Age at referral, distance travelled, and neonatal survival rate. All except five infants were referred within five days of birth

\begin{tabular}{|c|c|c|c|c|c|c|c|c|}
\hline \multirow{2}{*}{$\begin{array}{c}\text { Distance in miles } \\
(\mathrm{km})\end{array}$} & \multicolumn{2}{|c|}{ Age $<4$ hours } & \multicolumn{2}{|c|}{ Age 4-24 hours } & \multicolumn{2}{|c|}{ Age $>24$ hours } & \multicolumn{2}{|c|}{ All ages } \\
\hline & Total & Survived & Total & Survived & Total & Survived & Total & Survived \\
\hline $\begin{array}{l}0-<5(0-<8 \cdot 0) \\
5-<10(8 \cdot 0-<16 \cdot 0) \\
10-<15(16 \cdot 0-<24 \cdot 1) \\
15-<20(24 \cdot 1-<32 \cdot 2) \\
20-<50(32 \cdot 2-<80 \cdot 5)\end{array}$ & $\begin{array}{r}51 \\
25 \\
23 \\
1 \\
2\end{array}$ & $\begin{array}{r}34 \\
14 \\
7 \\
0 \\
2\end{array}$ & $\begin{array}{r}20 \\
24 \\
8 \\
3 \\
4\end{array}$ & $\begin{array}{r}16 \\
17 \\
6 \\
0 \\
1\end{array}$ & $\begin{array}{r}21 \\
11 \\
8 \\
8 \\
13\end{array}$ & $\begin{array}{r}16 \\
8 \\
7 \\
5 \\
9\end{array}$ & $\begin{array}{l}92 \\
60 \\
39 \\
12 \\
19\end{array}$ & $\begin{array}{l}66(72 \%) \\
39(65 \%) \\
20(51 \%) \\
5(42 \%) \\
12(63 \%)\end{array}$ \\
\hline Total & 102 & $57(56 \%)$ & 59 & $40(68 \%)$ & 61 & $45(74 \%)$ & 222 & $142(64 \%)$ \\
\hline
\end{tabular}


THE JOURNEY

The condition of $87\left(39^{\circ}\right.$ ) of the infants-mostly those initially in "bad" condition-improved during the journey, as judged by disappearance of cyanosis and return of the heart rate to normal; the condition of 126 infants $\left(57_{0}^{\circ}\right)$-largely those in "moderate" or "good" condition when collected-remained static; and the condition of nine infants $\left(4^{\circ}, 1\right)$ deteriorated. Four of these nine infants died in the ambulance. One had already had a cardiac arrest when our staff arrived and died after resuscitation of intraventricular and pulmonary haemorrhage; one died from intrauterine pneumonia and septicaemia; one died from hyaline membrane disease and a peneumothorax; and the other died from the effects of severe birth asphyxia.

Rectal temperatures were recorded from 128 infants just before and just after the journey. The mean value increased from $36.0 \mathrm{C}$ (range $29 \cdot 0-39 \cdot 3 \mathrm{C}$ ) to $36 \cdot 7^{\circ} \mathrm{C}$ (range $31 \cdot 0-39 \cdot 6 \mathrm{C}$ ). Temperatures below $35.0^{\circ} \mathrm{C}$ were recorded from 46 infants before transfer, and 29 afterwards. The temperature of 78 infants increased during the journey, in 33 infants it stayed constant, and in 17 it fell.

\section{FOLLOW UP}

The infants are being followed up, either at our own hospital using previously described methods ${ }^{12}$ or by paediatricians at the referring hospitals. The eventual outcome for the infants will be reported when they are old enough for definite conclusions to be reached.

\section{Discussion}

TRANSPORT SYSTEM

The referred infants had usually been born well before term and they were often suffering from serious respiratory illnesses. Though $109(49 \%)$ needed mechanical ventilation in transit, only nine $(4 \%)$ were thought to deteriorate and only four died during the journey. No relation between the distance travelled and survival rate could be shown. We conclude, therefore, that when trained staff collect the infants, using a transport incubator which has facilities for warming, oxygenating, monitoring, and, if necessary, mechanically ventilating a sick infant, transfer to a referral centre can safely be accomplished within a radius of 50 miles.

The transport incubator used during most of the study period (the Vickers 77) performed its function satisfactorily. It has the important advantage of being provided with a mechanical ventilator which can be set to produce the pressure waveforms required for ventilating infants with hyaline membrane disease. ${ }^{9}$ The ventilator design would be improved, however, if better methods were available for varying the inspired oxygen concentration, applying a positive end-expiratory pressure during ventilation, and administering CPAP during spontaneous breathing. The equipment for monitoring body temperature, heart rate, and inspired oxygen concentration that we built into the incubator proved most useful. Before this equipment was available we had often found it difficult to assess the condition of infants during the journey, particularly since they travel wrapped up.

\section{IMMEDIATE OUTCOME FOR THE INFANTS}

The survival rates according to birth weight for the transported infants who weighed $2000 \mathrm{~g}$ or less were not very different from the rates for all infants of like weight born in England and Wales, even though the transported infants were often seriously ill. The comparatively worse results for infants weighing more than $2000 \mathrm{~g}$ were partly because 10 of them died from lethal congenital malformations.

If the infants had not been transferred their chances would often have been poor. For example, most, if not all, of the 147 $(66 \%)$ who needed mechanical ventilation in transit or later would probably have died because adequate facilities for this type of treatment were not available in the referring hospitals.
Thus the risks to a sick infant of transporting him to a referral centre are much less than the risks of leaving him in a hospital that is not staffed or equipped for neonatal intensive care.

The outlook for some of the infants might have been better if they had been referred earlier and if effective means had always been available in the referring hospitals for resuscitation and the maintenance of a normal body temperature. Seventy-four $(33 \%)$ infants were thought to have been asphyxiated at birth and $70(32 \%)$ were in a "bad" condition, with severe respiratory failure, when our staff arrived. We think that this problem could largely be solved by ensuring that all doctors and nurses who are concerned with the care of the infants in the referring hospitals are fully trained in resuscitation, and resuscitation trolleys with radiant heaters mounted over them are always available in the labour wards and special care nurseries. Then most of even the most severely ill infants could probably be kept adequately warmed and oxygenated until collected.

The survival rates of infants born in this hospital weighing $2000 \mathrm{~g}$ or less were higher than the national rates, which suggests that it might sometimes be preferable to transfer the mother of an infant of low birth weight before delivery rather than transport the infant. This would also have the important advantage that mother and infant are not separated.

\section{EVENTUAL PROGNOSIS}

The infants in this study were too young for detailed developmental assessment, but the available evidence suggests that their eventual prognosis should be good. Recent follow-up studies of infants with hyaline membrane disease (who accounted for $50 \%$ of our survivors) show that their lung function and intelligence prove almost always to be normal. ${ }^{13-15}$ Furthermore, the later prognosis of infants of low birth weight, even those weighing $1500 \mathrm{~g}$ or less (who made up $35 \%$ of the survivors), seems to have improved considerably since the introduction of intensive care methods. ${ }^{12}{ }^{16}$ In the past from one-third to two-thirds of these infants were subsequently found to be handicapped. ${ }^{16}{ }^{17}$ Our own data for infants weighing $1500 \mathrm{~g}$ or less and bcre in 1966-7012 gave a handicap rate of $9.5 \%$ at a mean age of 5 years, with no detectable difference between infants born in this hospital and those who were transported from elsewhere.

\section{ORGANISATION OF NEONATAL CARE}

Regional neonatal and perinatal centres have now been set up in several countries and evidence has been presented that neonatal and perinatal mortality have been reduced, not only in the units themselves but also in the hospitals and communities they serve. $^{719}$ More important, there is accumulating evidence that properly applied intensive care methods decrease the incidence of mental and physical handicap among the survivors and should lead to a net reduction in the number of handicapped people entering the community. ${ }^{719-21}$

Little attempt has so far been made to set up regionalised services for neonatal or perinatal care in this country, yet the cost of providing such services need not be very great. For example, in the North-east Thames Region a neonatal intensive care service could probably be provided if 35 intensive care beds were sited in two or three major centres that already have special care nurseries. ${ }^{3}$ Money spent in this way would almost certainly be more than offset by the saving resulting from the reduction in the numbers of surviving handicapped individuals. Our data supply further evidence that regionalisation of neonatal and perinatal care should be given high priority in the allocation of Health Service resources.

We thank the medical and nursing staff of the neonatal unit for their devoted care of the infants; the medical physics department, particularly Mr J C Clifton and Mr M H Gondal for their help and encouragement; the staff of the referring hospitals, the London Ambulance Service, 
and the Metropolitan Police for their unfailing co-operation; Dr Eva Alberman for survival rates of infants in England and Wales given in table I; and Dr Ann Stewart for her helpful advice.

Requests for reprints should be addressed to Dr E O R Reynolds, Department of Paediatrics, University College Hospital, London WCl.

\section{References}

' Klaus, M H, and Fanaroff, A A, Care of the High-Risk Neonate. Philadelphia, Saunders, 1973.

Gregory, G A, et al, New England fournal of Medicine, 1971, 284, 1333.

${ }^{3}$ Expert Group on Special Care for Babies, Reports on Public Health and Medical Subjects, No. 127. London, HMSO, 1971.

- Segal, S, Pediatric Clinics of North America, 1966, 13, 1195.

5 Storrs, C N, and Taylor, M R H, British Medical fournal, 1970, 3, 328.

' Segal, S (editor), Transport of the High Risk Newborn. Montreal, Canadian Paediatric Society, 1972.
'Swyer, P R, and Goodwin, J W (editors), Regional Services in Reproductive Medicine. Montreal, Canadian Paediatric Society, 1973.

' Blake, A M, et al, Lancet, 1970, 1, 25.

${ }^{9}$ Reynolds, E O R, International Anesthesiology Clinics, 1974, 12, 259.

1 " Baum, J D, and Scopes, J W, Lancet, 1968, 1, 672.

$"$ Lubchenco, L O, et al, Pediatrics, 1963, 32, 793.

12 Stewart, A L, and Reynolds, E O R, Pediatrics, 1974, 54, 1974.

13 Stahlman, M, et al, Pediatric Clinics of North America, 1973, 20, 433

is Bryan, M H, Levison, H, and Swyer, P R, Bulletin de Physio-Pathologie Respiratoire. 1973, 9, 1587.

15 Fisch, R O, et al, fournal of Pediatrics, 1975, 86, 497

${ }^{16}$ Davies, P A, and Stewart, A L, British Medical Bulletin, 1975, 31, 85

${ }^{17}$ Drillien, C M, Archives of Disease in Childhood, 1958, 33, 10.

18 McDonald, A, Children of Very Low Birth Weight. London, Heinemann, 1967.

19 Cassady, G, in Clinical Perinatology, ed S Aladjem and A K Brown, p 422. St Louis, Mosby, 1974.

20 Manciaux, M, in Perinatal Medicine, ed. H Bossart et al, p 13 Bern, Huber, 1973.

${ }^{21}$ Office of Health Economics. Mental Handicap. London, OHE, 1973.

\title{
Aminocaproic acid and menstrual loss in women using intrauterine devices
}

\author{
J M KASONDE, J BONNAR
}

British Medical fournal, 1975, 4, 17-19

day during menstruation for the subsequent four periods. For the next four periods they took the treatment during cycles 6 and 8 only.

The second group consisted of 35 women presenting with IUD menorrhagia, irrespective of the type of device. These women were studied through six consecutive menstrual collections. The first was a baseline measurement; the next three were treatment periods during which they received $3 \mathrm{~g}$ EACA four times a day taken as a powder dissolved in water. The last two periods were without treatment.

A controlled study of the effect of aminocaproic acid $3 \mathrm{~g}$ six-hourly taken by mouth during menstruation was carried out on 56 women for eight months from the time of insertion of a Lippes $D$ intrauterine device (IUD). Thirty-five women presenting with menorrhagia in association with an IUD were also treated during three out of six consecutive menses. A highly significant reduction in menstrual loss was observed during treatment in both groups.

\section{Introduction}

Excessive menstrual bleeding is the commonest complication of intrauterine contraceptive devices (IUDs) and is responsible for their discontinuance in up to $20 \%$ of users. ${ }^{1-4}$ Since aminocaproic acid (EACA), an antifibrinolytic agent, effectively controls menorrhagia not related to IUDs we have studied its effects on menstrual blood loss in women using IUDs.

\section{Patients and method}

Two groups of women were studied, all of whom gave full and informed consent. The first group consisted of 56 women requesting intrauterine contraception. They had one menstrual collection measured before insertion and eight consecutive collections measured after insertion. The patients were allocated to treatment and control groups matched for pre-insertion menstrual loss and stratified to cover a range of losses from 5 to $100 \mathrm{ml}$ (table I). All were fitted with Lippes D IUDs. The treated women received $3 \mathrm{~g}$ EACA four times a day for seven days from the date of insertion, then $3 \mathrm{~g}$ four times a

Nuffield Department of Obstetrics and Gynaecology, John Radcliffe Hospital, Oxford

J M KASONDE, MRCOG, research fellow

J BONNAR, MD, FRCOG, clinical reader

TABLE I-Pre-insertion blood loss in 56 treated women and controls

\begin{tabular}{|c|c|c|c|}
\hline \multirow{2}{*}{$\begin{array}{l}\text { No. of } \\
\text { Patients }\end{array}$} & \multicolumn{3}{|c|}{ Blood Loss (ml) } \\
\hline & Range & $\begin{array}{c}\text { Treated Women } \\
(\mathrm{n}=28)\end{array}$ & Controls $(n=28)$ \\
\hline 16 & $5-20$ & $\begin{array}{r}5.4 \\
8.7 \\
9.0 \\
9.2 \\
11.8 \\
14.2 \\
16.9 \\
19.8\end{array}$ & $\begin{array}{r}7.9 \\
10.7 \\
12.2 \\
12.3 \\
15.9 \\
16.2 \\
16.6 \\
17.6\end{array}$ \\
\hline 16 & $>20-40$ & $\begin{array}{l}20 \cdot 3 \\
20 \cdot 6 \\
22 \cdot 2 \\
23 \cdot 2 \\
23 \cdot 4 \\
29 \cdot 7 \\
30 \cdot 1 \\
35 \cdot 4\end{array}$ & $\begin{array}{l}20 \cdot 7 \\
21.6 \\
24.4 \\
25.5 \\
26.5 \\
29.8 \\
30.3 \\
33.7\end{array}$ \\
\hline 10 & $>40-60$ & $\begin{array}{l}46 \cdot 1 \\
49.6 \\
49.9 \\
53 \cdot 2 \\
60.0\end{array}$ & $\begin{array}{l}40 \cdot 6 \\
40 \cdot 9 \\
43 \cdot 2 \\
47.4 \\
51 \cdot 8\end{array}$ \\
\hline 6 & $>60-80$ & $\begin{array}{l}62.9 \\
63 \cdot 2 \\
67.7\end{array}$ & $\begin{array}{l}64.9 \\
71 \cdot 6 \\
80 \cdot 0\end{array}$ \\
\hline 4 & $>80-100$ & $\begin{array}{l}96.9 \\
99.0\end{array}$ & $\begin{array}{l}84 \cdot 8 \\
87 \cdot 2\end{array}$ \\
\hline 4 & $>100$ & $\begin{array}{l}124 \cdot 7 \\
131 \cdot 3\end{array}$ & $\begin{array}{l}103 \cdot 2 \\
157 \cdot 4\end{array}$ \\
\hline \multicolumn{2}{|c|}{ Mean } & $43 \cdot 0$ & $42 \cdot 7$ \\
\hline
\end{tabular}

All patients gave a full medical history and underwent clinical examination, including gynaecological assessment.

All tampons and sanitary towels used were collected in polyethylene bags numbered for each day of bleeding. Blood loss was measured by a modified alkaline haematin method. ${ }^{5}$ The pads and tampons were soaked in $5 \%$ sodium hydroxide for $\mathbf{4 8}$ hours. The 